\title{
A simple electrochemical method to monitor an azo dye reaction with a liver protein
}

\author{
Elsa Maria Materón ${ }^{\mathrm{a}, \mathrm{b}, *}$, Reinaldo Marchetto ${ }^{\mathrm{a}}$, Angela Regina Araujo ${ }^{\mathrm{a}}$, Jaime Vega-Chacon ${ }^{\mathrm{a}}$, \\ Maria I. Pividori ${ }^{\mathrm{c}}$, Miguel Jafelicci Jr. ${ }^{\mathrm{a}}$, Flavio M. Shimizu ${ }^{\mathrm{b}, * *}$, Osvaldo N. Oliveira Jr. ${ }^{\mathrm{b}}$, \\ Maria Valnice Boldrin Zanoni ${ }^{\mathrm{a}, * * *}$ \\ a Institute of Chemistry, São Paulo State University (UNESP), 14801-970 Araraquara, SP, Brazil \\ b São Carlos Institute of Physics, University of São Paulo, P.O Box 369, 13560-970 São Carlos, SP, Brazil \\ ${ }^{\mathrm{c}}$ Institute of Chemistry, Autonomous University of Barcelona (UAB), 08193 Bellaterra, Catalonia, Spain
}

\begin{abstract}
A B S T R A C T
Disperse Orange 37 (DO37) is an efficient azo dye for dyeing synthetic textile materials owing to its resistance to degradation that may also be harmful to humans as DO37 is not entirely eliminated in wastewater treatment. In this paper, we demonstrate that DO37 is bleached by reduced glutathione (GSH) in a reaction catalyzed by glutathione-s-transferase (GST), a phase II detoxification enzyme. The reaction included a nucleophilic attack involving sulfhydryl groups, confirmed using density functional theory (DFT) calculations. DO37 also induced quenching in the fluorescence of GST through static suppression. The reaction was determined using differential pulse voltammetry (DPV) by monitoring the oxidation peak at $0.65 \mathrm{~V}$ of GSH sulfhydryl group. Quantitative estimation of the product reaction could be made by measuring an additional oxidation peak at $0.91 \mathrm{~V}$ which increased linearly with DO37 concentration. These electrochemical determinations were made possible by preconcentrating the reaction product on a graphite-epoxy electrode with immobilization of GST onto magnetite nanoparticles. Straightforward biological implications from the results are associated with the known toxicity of azo dyes such as DO37, which has been proven here to interact strongly with both GSH and the liver enzyme GST, and may induce hepatocarcinogenesis or other types of cancer.
\end{abstract}

\section{Introduction}

Effluents from the textile industry contain many chemical pollutants that must be properly treated or disposed of to avoid contamination of wastewater treatment plants, surface water and drinking water. Among such effluents are several types of dyes, especially the toxic and carcinogenic azo dyes [1], which have been found harmful to organisms including humans and genotoxic for bacterial and mammalian cells $[2,3]$. Azo dyes are difficult to degrade by bacteria used in biological effluent treatments owing to their $-\mathrm{N}=\mathrm{N}$ - and electron withdrawing groups that promote electron deficiency, thus causing significant environmental contamination in view of the huge volume of wastewater generated [4]. The hydrophobic, slightly soluble non-ionic aromatic disperse dyes are the most used for dyeing synthetic fabrics. The orange 37 dye and products generated even after treatment of water containing azo dyes showed mutagenic activity in Salmonella mutagenicity assays
[5-7].

Azo dyes also interact with enzymes in the liver, e.g. glutathione-stransferase (GST) and cytochrome P450 (CYP) involved in the conversion of xenobiotic compounds to facilitate their elimination [8]. Exposure to such toxic compounds as azo dyes may hamper the GST catalysis of the conjugation of glutathione (GSH) to a wide variety of endogenous and exogenous electrophilic compounds [9], thus leading to cell proliferation in the early stages of oncogenesis [10-12]. Understanding the interaction between azo dyes, GSH and GST is therefore crucial for establishing the role of detoxification enzymes against toxic compounds, which may be useful for developing more effective methods to degrade azo dyes in water treatment plants.

In this paper, we determine the mechanisms of interaction between DO37 and GST (and GSH) using a combination of experimental and theoretical methods. The parameters of reaction kinetics and the groups involved in the reaction were determined through optical techniques

\footnotetext{
* Corresponding author. Institute of Chemistry, São Paulo State University (UNESP), 14801-970 Araraquara, SP, Brazil.

*** Corresponding author.

**** Corresponding author.

E-mail addresses: elsa_materon@yahoo.com (E.M. Materón), fmshimizu@yahoo.com.br (F.M. Shimizu), boldrinv@iq.unesp.br (M.V.B. Zanoni).
} 

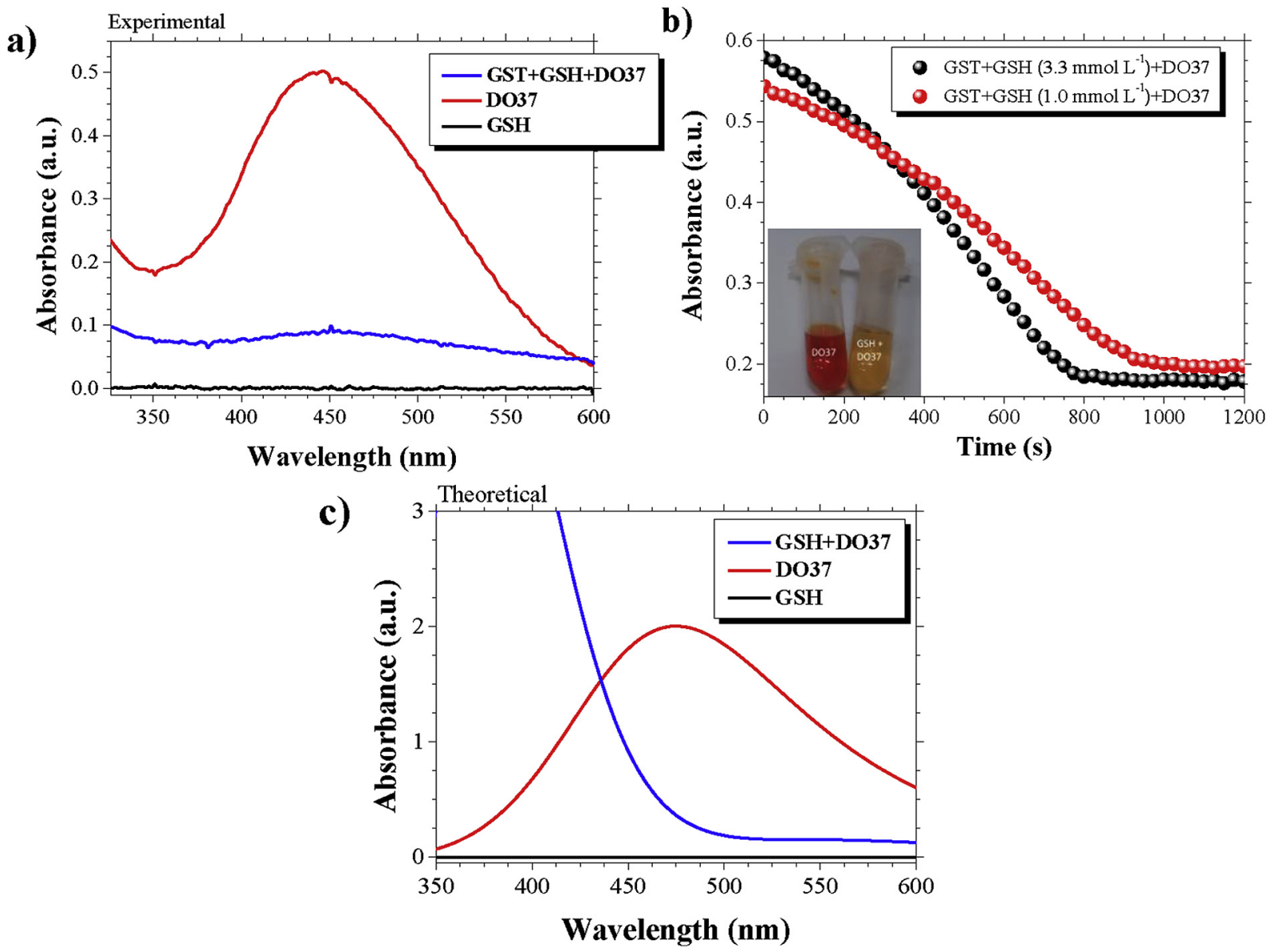

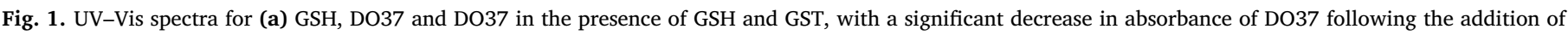

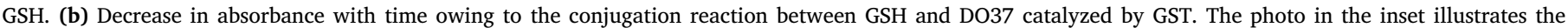
bleaching of the dye. (c) Theoretical UV-Vis spectra obtained from DFT modeling using RTD B3LYP 6-31 g basis set.

while density functional theory (DFT) calculations confirmed the mechanism proposed. Most significantly, we were able to identify the reaction product via electrochemical measurements, which was made possible by preconcentrating the product on the electrode. The strategy adopted consisted in covalently coupling GST to magnetic nanoparticles (MNP) functionalized with carboxyl group (-COOH), then deposited onto a magneto graphite-epoxy electrode.

\section{Experimental}

\section{Chemicals and preparation of solutions}

Glutathione-s-transferase from equine liver (GST), reduced LGlutahione (GSH), N-hydroxysuccinimide (NHS), 1-Ethyl-3-(3-dimethyllaminopropyl) carbodiimide (EDC), ammonia, citric acid and acetone were purchased from Sigma-Aldrich (St. Loius, MO, USA). $0.1 \mathrm{~mol} \mathrm{~L}^{-1}$ at $\mathrm{pH} 6.5$ phosphate buffer solution (PBS) was prepared with $\mathrm{NaH}_{2} \mathrm{PO}_{4}$ and $\mathrm{Na}_{2} \mathrm{HPO}_{4}$. Disperse orange 37 (DO37) was dissolved in acetone, while GSH, GST, EDC and NHS solutions were prepared in PBS.

\section{Synthesis and characterization of MNPs}

Magnetite nanoparticles (MNPs) were synthesized using the coprecipitation method [13], where $\mathrm{FeCl}_{3} \cdot 6 \mathrm{H}_{2} \mathrm{O}$ and $\mathrm{FeCl}_{2} \cdot 4 \mathrm{H}_{2} \mathrm{O}$ in $2: 1 \mathrm{M}$ ratio are dissolved in $40 \mathrm{~mL}$ of deionized water. After purging the solution with argon gas, $6 \mathrm{~mL}$ of ammonia solution were added under vigorous mechanical stirring. The resulting black suspension was transferred to a three-necked round bottom flask equipped with a reflux condenser. The temperature was increased to $90{ }^{\circ} \mathrm{C}$ and maintained under argon atmosphere for $30 \mathrm{~min}$. Then, $3 \mathrm{~mL}$ of citric acid solution ( $0.6 \mathrm{~g} \mathrm{~mL}^{-1}, \mathrm{pH}$ adjusted to 7 with ammonia solution) were added to the suspension, and after $7 \mathrm{~h}$ the nanoparticles were dialyzed against deionized water for $48 \mathrm{~h}$. Identification of functional groups in MNPs was performed with a Perkin Elmer Frontier Fourier transform infrared spectrometer (FTIR). Dried samples were dispersed in $\mathrm{KBr}$ pellets and scanned over the range of $4000-400 \mathrm{~cm}^{-1}$ with a nominal resolution of $4.0 \mathrm{~cm}^{-1}$. Transmission Electron Microscopy (TEM) was used to monitor MNPs morphology in the colloidal suspension using a Leo 906E (Zeiss) TEM microscope at $100 \mathrm{kV}$. A drop of the colloidal suspension $(100 \mu \mathrm{g} \mathrm{Fe} / \mathrm{mL})$ was dispersed and dried on a copper grid covered with collodion and carbon prior to the experiment. A field-emission gun scanning electron microscopy (FEG-SEM), JEOL model 7500F, with electron beam energy of $25 \mathrm{keV}$ was also used to characterize the MNPs.

Reaction between reduced L-Glutahione (GSH) and disperse orange 37 dye catalyzed by GST

UV-Vis measurements were made in a BEL Photonics spectrophotometer with a $1.5 \mathrm{~mL}$ quartz cuvette at $25^{\circ} \mathrm{C}$. Fluorescence measurements were performed in a Varian Cary Eclipse fluorescence spectrophotometer with a thermostatic sample compartment at $37^{\circ} \mathrm{C}$ with $1.5 \mathrm{~mL}$ quartz cuvette with a $1.0 \mathrm{~cm}$ path length. Fluorescence excitation and emission slit widths were set for $5 \mathrm{~nm}$ bandpass for all measurements, performed at $290 \mathrm{~nm}$ (excitation) and $335 \mathrm{~nm}$ (emission). Attenuated total reflection-Fourier transform infrared (ATR-FTIR) 


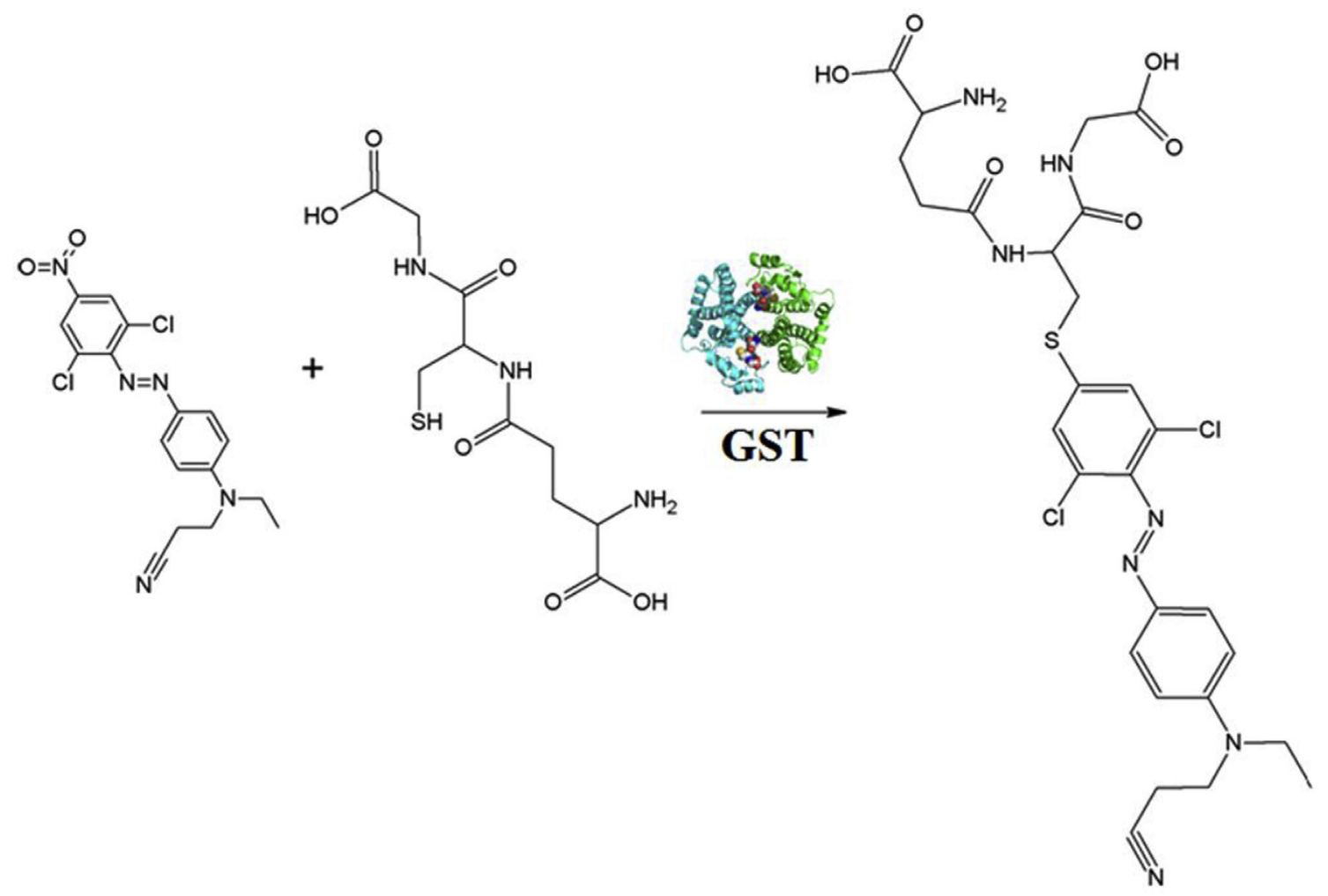

Fig. 2. Chemical structure of disperse orange 37 (DO37), glutathione (GSH), and the product catalyzed by GST.
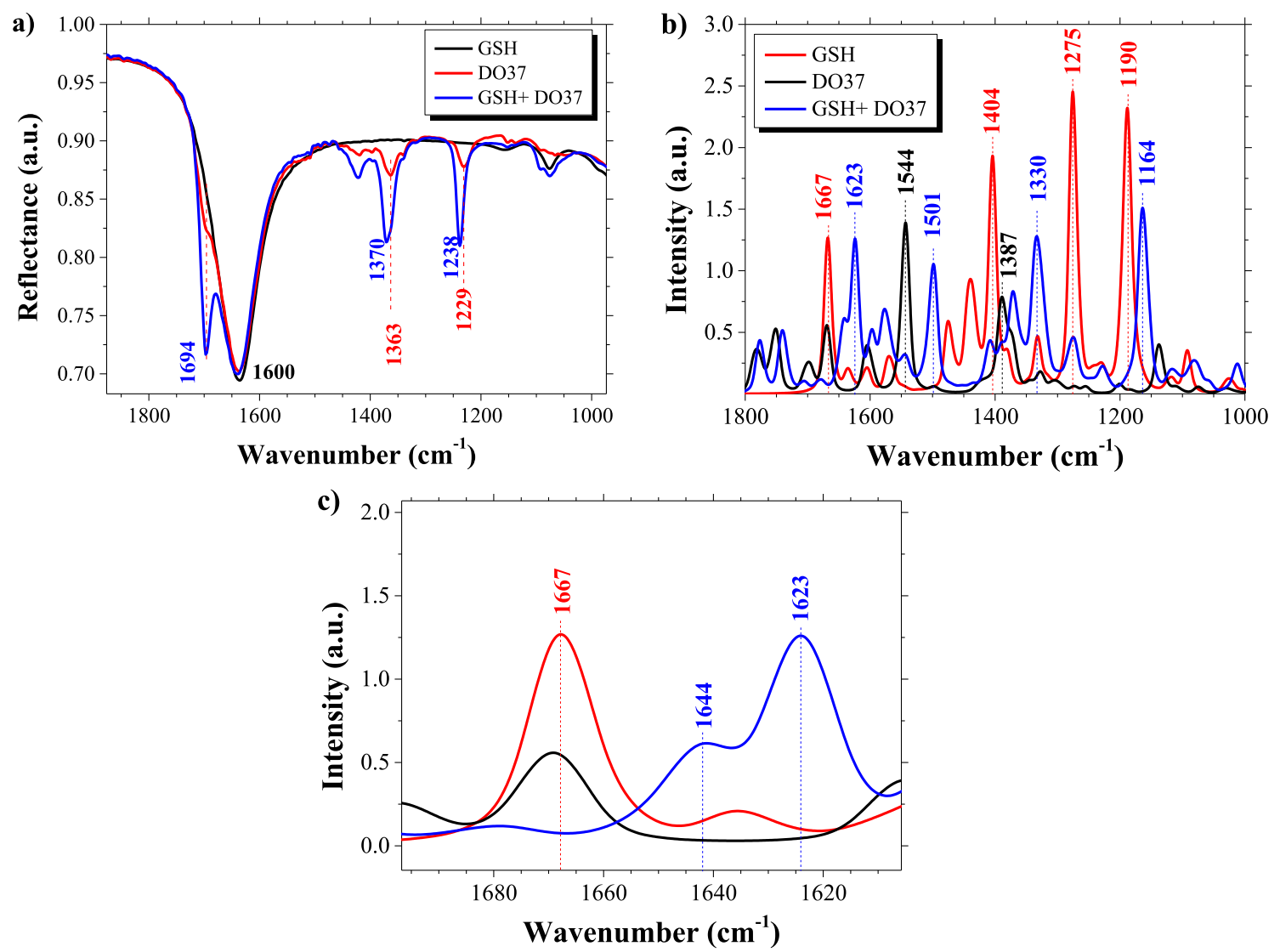

Fig. 3. (a) ATR-FTIR spectra of GSH (black line), DO37 (red line), and product of the reaction between them (blue line), (b) theoretical FTIR spectra, and (c) zoomed figure with the theoretical spectra. (For interpretation of the references to colour in this figure legend, the reader is referred to the Web version of this article.) 


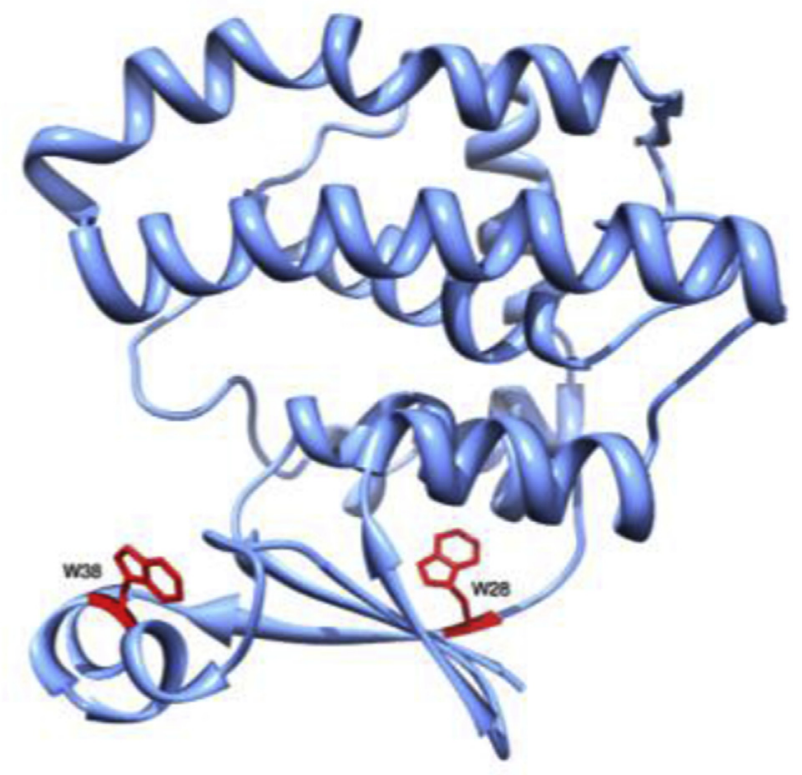

Fig. 4. Ribbon representation of one monomer of human GST. The triptophan residues are red, both with equal accessibility to the solvent. (For interpretation of the references to colour in this figure legend, the reader is referred to the Web version of this article.)

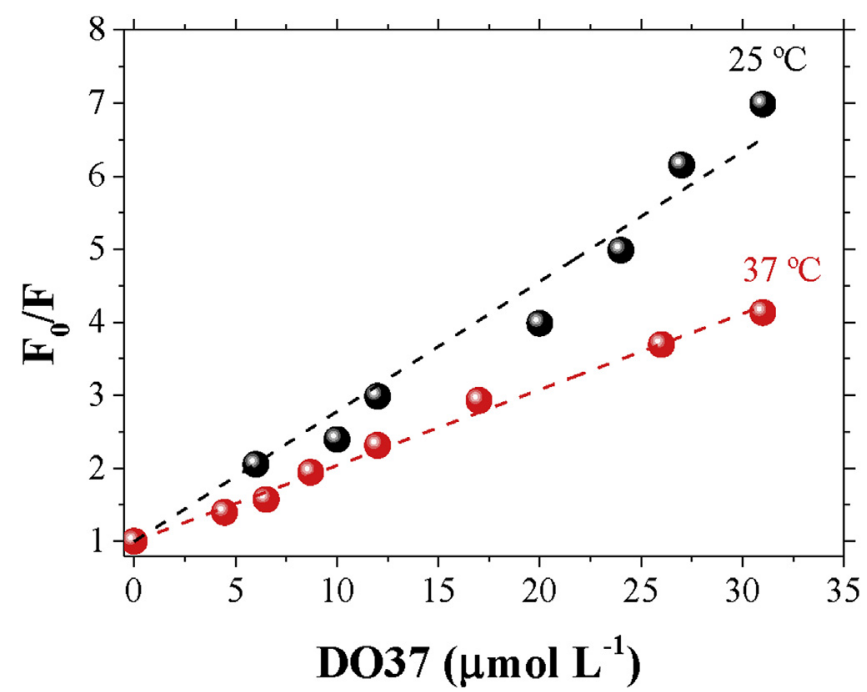

Fig. 5. Stern-Volmer plots at $25^{\circ} \mathrm{C}$ and $37^{\circ} \mathrm{C}$. Fluorescence was measured (excitation, $290 \mathrm{~nm}$; emission, $335 \mathrm{~nm}$ ) after each aliquot addition of DO37 to the GST sample. The slope of the Stern-Volmer plot represents the association constant of the complex formed.

spectra of GSH, DO 37 and GSH-DO37 were measured with a VERTEX 70/BRUKER FTIR, using the PLATINUM Diamond ATR accessory with a diamond crystal plate. Theoretical UV-Vis and FTIR spectra were calculated with density functional theory (DFT) using Gaussian 03 Revision B.04 software employing the functional B3LYP Tamm-Dancoff (TD) approximation with the basis set 6-31G using water as solvent for the SCF convergence on geometry.

Electrochemical measurements were performed in an Autolab potentiostat at room temperature, using a standard three-electrode electrochemical cell. The working electrode was a $3 \mathrm{~mm}$ magneto graphiteepoxy electrode (m-GEC) [14], made by hand mixing epoxy resin and graphite powder in a $1: 4(\mathrm{w} / \mathrm{w})$ ratio, whose paste filled a cylindrical PVC sleeve body ( $6 \mathrm{~mm}$ i.d.) with copper plate as electrical contact, and a small neodymium magnet ( $3 \mathrm{~mm}$ i.d.) was placed on the electrode center. The electrode was cured at $40^{\circ} \mathrm{C}$ for 1 week to obtain a rigid composite [15]. A Pt wire was used as counter electrode and $\mathrm{Ag} / \mathrm{AgCl} /$ $3 \mathrm{M} \mathrm{KCl}$ was the reference electrode.

\section{Enzyme immobilization for electrochemical detection}

The MNPs modified with $\mathrm{COOH}$ group were activated by NHS/EDC at a proportion of 2:1 for $40 \mathrm{~min}$ and washed with $0.1 \mathrm{~mol} \mathrm{~L}^{-1}$ phosphate buffer ( $\mathrm{pH}$ 6.5) $[16,17]$. The GST enzyme was immobilized on MNPs functionalized with carboxylic group previously activated with NHS/EDC by adding $100 \mu \mathrm{L}$ of $2.5 \mathrm{mg} \mathrm{mL}^{-1}$ stock solution of GST to $500 \mu \mathrm{L}$ of nanoparticles solution for $45 \mathrm{~min}$. The magnetic nanoparticles were washed and exposed to different solutions containing $5.6 \times 10^{-6}$, $1.69 \times 10^{-5}, 2.26 \times 10^{-5}, 2.82 \times 10^{-5}, 4.0 \times 10^{-5} \mathrm{~mol} \mathrm{~L}^{-1}$ of DO37 dye with and without $5.0 \times 10^{-4} \mathrm{~mol} \mathrm{~L}^{-1}$ of GSH during $20 \mathrm{~min}$. Subsequently, $50 \mu \mathrm{L}$ of the solution containing nanoparticles were added for $2 \mathrm{~min}$ on the magnetic electrode. The dye solutions mentioned above were evaluated using differential pulse voltammetry (DPV). All the MNPs, DO37 and GSH solutions were prepared fresh daily.

\section{Results and discussion}

\section{Interaction between GSH and DO37 catalyzed by GST}

Fig. 1a illustrates the bleaching of DO37 (orange solution) in acetone/phosphate buffer solution upon interacting with GSH that shows no absorbance in the range studied. These UV-Vis spectra were taken at $\mathrm{pH} 6.5$ in the presence of GST enzyme, with the absorbance being reduced by $82.1 \%$ after $4 \mathrm{~min}$ of reaction. In subsidiary experiments we observed a similar bleaching without GST but with the bleaching effect occurring at a much lower rate. Fig. 1b shows that the rate of bleaching increases with the GSH concentration, as expected, with the solution becoming yellow according to the inset in the figure. The theoretical UV-Vis spectra in Fig. 1c calculated with B3LYP 6-31 g basis set from the optimized geometry in Fig. 2 give support to the reaction between DO37 and GSH catalyzed by GST, since the reaction product proposed here bonds covalently to the sulfhydryl group. The bleaching resulted in a band shift from $451 \mathrm{~nm}$ to $550 \mathrm{~nm}$. The large absorption at small wavelengths for the DO37 + GSH system corresponds to GSH absorption shifted from the theoretical value as predicted in Fig. S1.

GST is also known to catalyze the nucleophilic addition of tripeptide glutathione (GSH) for substrates with electrophilic functional groups [9,18-21]. The interaction between GSH and DO37 occurs by substitution nucleophilic aromatic reactions (SNAr). GST catalyzes the reaction between reduced glutathione (GSH) and different molecules through formation of a thioether bond between the sulfur atom of GSH and the substrate. Based on the structure of DO37 in Fig. 2, we may assume that chlorine $(\mathrm{Cl})$ atoms are weak deactivator of ortho and para directing, while $\mathrm{NO}_{2}$ is a strong deactivator. Since $\mathrm{NO}_{2}$ is activator for meta position, this will be the position adopted. In addition, $\mathrm{NO}_{2}$ works like a good outgoing group in SNAr reactions. Then, $\mathrm{NO}_{2}$ comes out and GSH enters by joining through the sulfur. When GSH enters, a loss of resonance occurs, thus producing the bleaching because the resonance of the electron pair in the sulfur is less efficient than the nitrogen pair. Still considering Fig. 2, we infer that bleaching is related to the loss of resonance in the dye structure owing to the chemical reaction with the sulfhydryl group of GSH. This conclusion is consistent with the catalytic induction of thioether conjugation between the endogenous tripeptide glutathione and xenobiotic compounds [9,22].

The molecular mechanisms involved in the reaction between DO37 and GSH catalyzed by GST in solution were probed with FTIR spectroscopy in the attenuated total reflectance (ATR) mode. Fig. 3a shows that interaction between GSH and DO37, GSH causes the appearance of the band at $1694 \mathrm{~cm}^{-1}$ assigned to $\mathrm{C}=\mathrm{C}$ symmetric stretching. The 


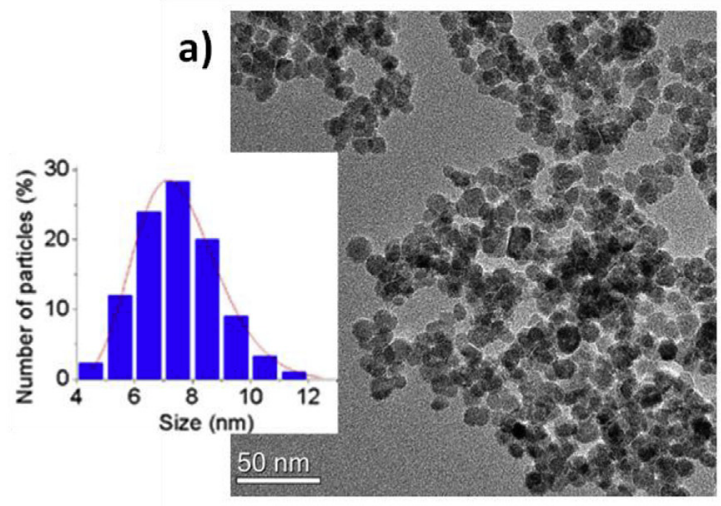

b)

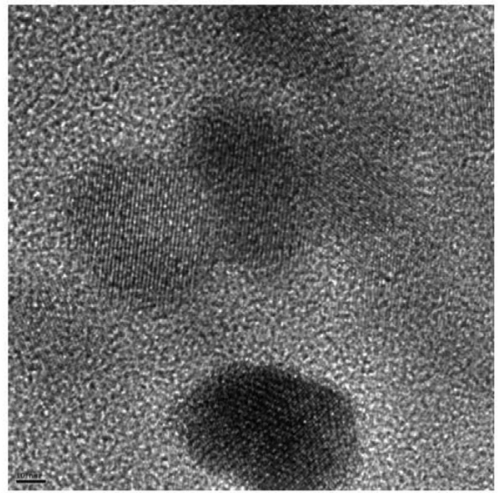

c)

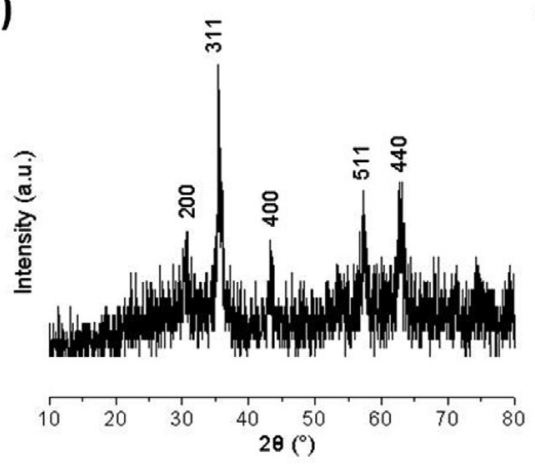

d)

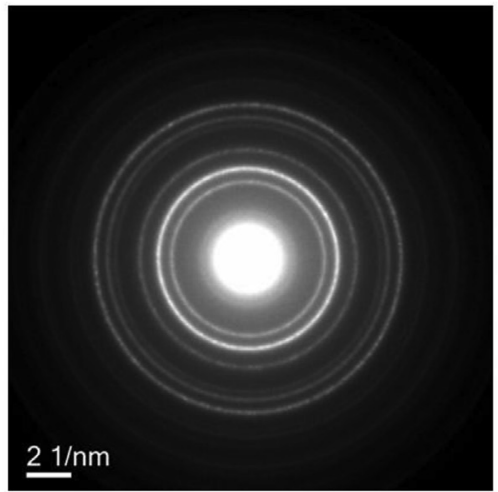

Fig. 6. Characterization of MNPs: (a) TEM image with the inset showing the distribution of particle size; (b) HR TEM image; (c) X-ray diffraction pattern, and (d) Electron diffraction pattern.
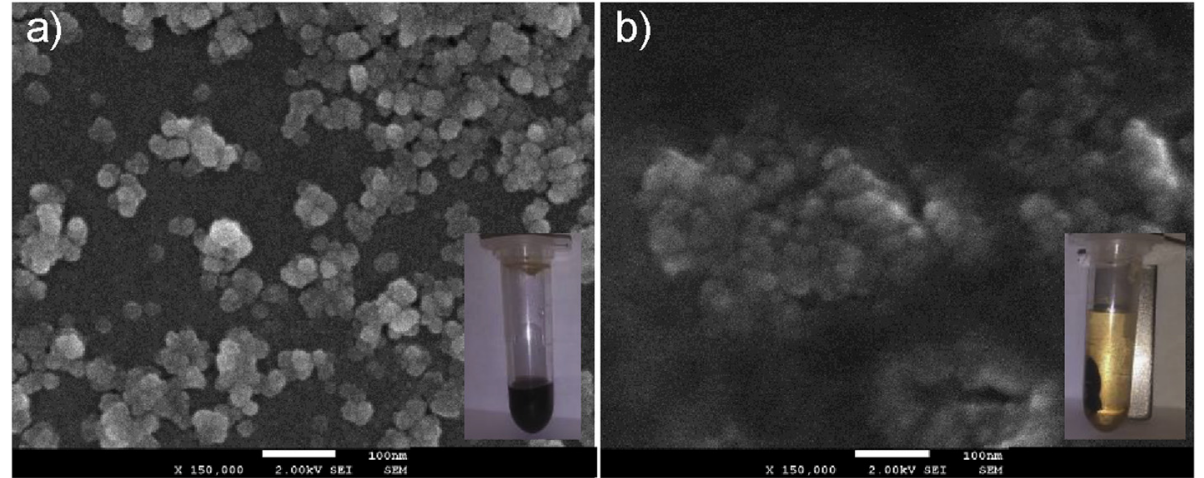

Fig. 7. FEG-SEM images of: (a) MNPs with carboxyl group and (b) MNP modified with GST enzyme.

main features of the experimental spectra could be reproduced in the theoretical spectra in Fig. 3b calculated with B3LYP 6-31 g basis set from optimized geometry. The smaller number of bands at experimental spectra is explained by the dependence of light penetration on sample which directly affects the intensity of bands, on the other hand the theoretical spectrum shows all possibilities of vibrational bands from the molecular structure. A shift of ca. $40-50 \mathrm{~cm}^{-1}$ toward higher wavenumbers was observed for the main vibrational bands of DO37 assigned to aromatic ring stretching (1667 and $1190 \mathrm{~cm}^{-1}, \mathrm{CN}$ antisymmetric stretching $\left(1404 \mathrm{~cm}^{-1}\right)$, and $\mathrm{NO}_{2}$ scissor $\left(1275 \mathrm{~cm}^{-1}\right)$ and for the GSH molecule with $\mathrm{C}=\mathrm{N}$ and $\mathrm{COH}$ scissor at 1544 and $1387 \mathrm{~cm}^{-1}$ ), respectively. This shift probably appears because the experimental spectra were obtained in solution. We recall, nevertheless, that the main features are reproduced in the theoretical spectra, in spite of the shift. The region of the spectra confirming the reaction between DO37 and GSH is shown in a zoomed image in Fig. 3c, where a new band appears at $1644 \mathrm{~cm}^{-1}$ that corresponds to the experimental band at $1694 \mathrm{~cm}^{-1}$ in the experimental spectra.
GSTs are usually found in the biological environment as dimers, with two active sites per dimer whose activities are independent of each other. Each active site consists of at least two binding regions, one very specific for glutathione (GSH) and another with specificity for the electrophiles, such as DO37. Therefore, DO37 interaction with GST was evaluated by fluorescence quenching as a means of proving the binding of the dye to the enzyme and the possible formation of GSH-DO37 product by GST catalysis. GST was excited at $290 \mathrm{~nm}$ to reach a selective excitation of the two tryptophan residues (W28 and W38) of each monomer Fig. 4.

The intrinsic fluorescence of GST was gradually quenched with increasing DO37 concentration. Various processes can result from the quenching, including excited state reactions, energy transfer, complex formation and dynamic processes [23]. The data in Fig. 5 obtained at $25^{\circ} \mathrm{C}$ and $37^{\circ} \mathrm{C}$ were represented in a Stern-Volmer plot where the relative GST fluorescence $\left(F_{O} / F\right)$ was plotted against DO37 concentration. The slope is equal to the Stern-Volmer quenching constant (KSV), as follows: 


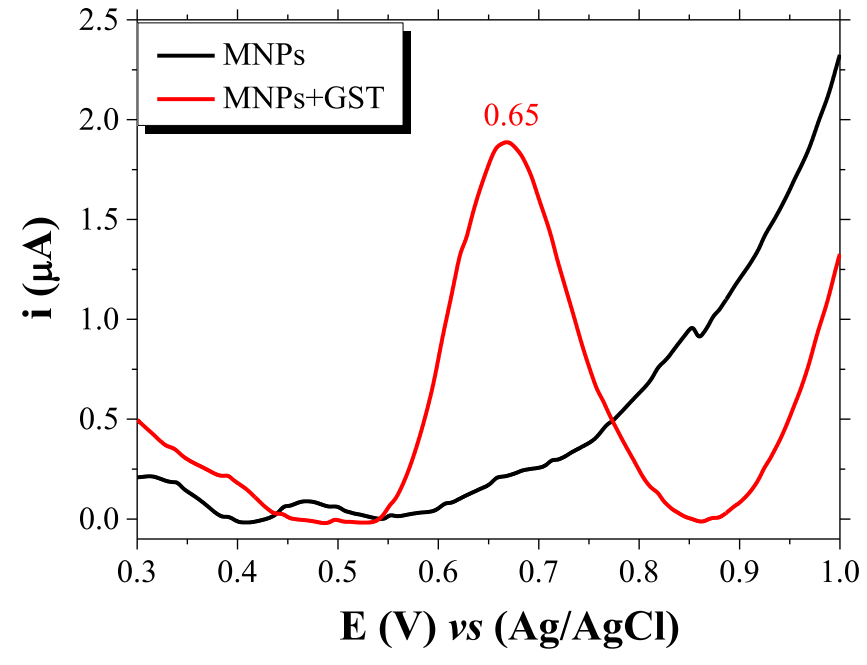

Fig. 8. Profile of differential pulse voltammetry of MNPs and MNPs modified with GST enzyme.

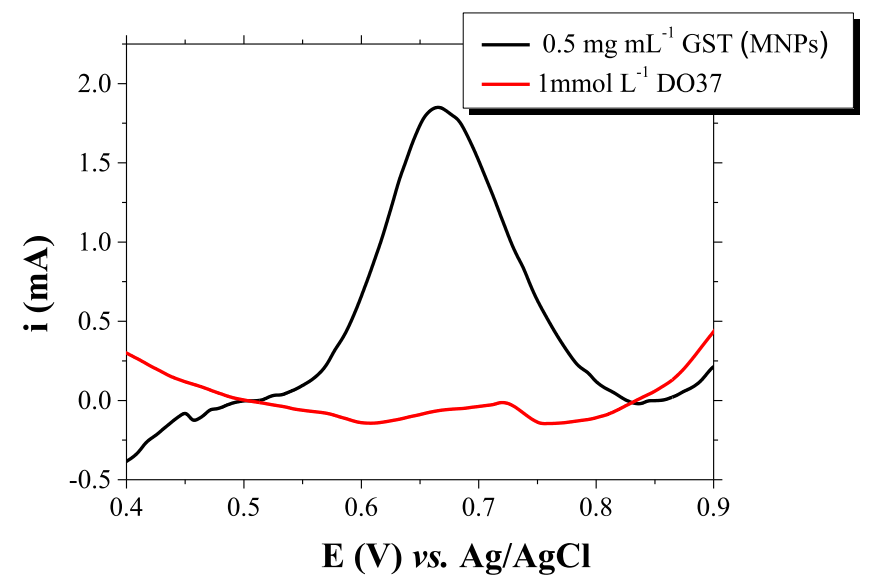

Fig. 9. Electrochemical response with differential pulse voltammetry of GST (black line), and after addition of $1 \mathrm{mmol} \mathrm{L}^{-1}$ of DO37 (red line). (For interpretation of the references to colour in this figure legend, the reader is referred to the Web version of this article.)

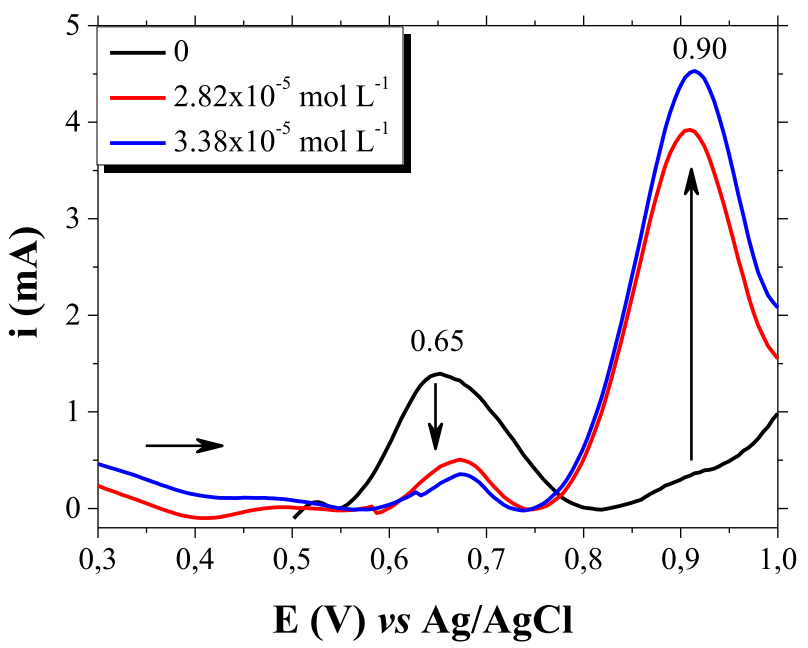

Fig. 10. Electrochemical response in DPV of GST with $1 \mathrm{mmol} \mathrm{L}^{-1} \mathrm{GSH}$ and $2.82 \times 10^{-5}$ and $3.38 \times 10^{-5} \mathrm{~mol} \mathrm{~L}^{-1}$ concentrations of DO37.

$\frac{F_{0}}{F}=1+\mathrm{KSV}[\mathrm{DO} 37]$
In this equation, $F_{O}$ and $F$ are the fluorescence intensities of GST in the absence and presence of DO37, respectively. The straight lines in Fig. 5 are indication that all tryptophan residues of GST are equally accessible to the dye [24]. In fact, the W28 and W38 residues are equally exposed to the solvent and consequently to DO37 interaction (Fig. 5).

The fluorescence quenching data can be explained by either a dynamic or static processes. In dynamic quenching the fluorophore and the quencher come into contact during the lifetime of the excited state, whereas static quenching refers to fluorophore-quencher complex formation [24]. One way to distinguish them is to examine the temperature dependence [23], as shown in Fig. 5. Dynamic quenching depends upon diffusion. Since higher temperatures result in larger diffusion coefficients, the bimolecular quenching constants are expected to increase with the temperature. In contrast, an increased temperature is likely to result in decreased stability of the complexes, and therefore smaller static quenching constants. So, for static quenching (complex formation), the increase in temperature leads to a decrease in the slope of the Stern-Volmer plots. From the measurements at two temperatures in Fig. 5 one concludes that static quenching occurs, in which case the quenching constant becomes the association constant. Therefore, the association constant $\left(K_{a}\right)$ for GST-DO37 complex are $K_{a}=1.79 \times 10^{5} \mathrm{~mol} \mathrm{~L}^{-1}$ and $K_{a}=1.05 \times 10^{5} \mathrm{~mol} \mathrm{~L}^{-1}$ for $25^{\circ} \mathrm{C}$ and $37^{\circ} \mathrm{C}$, respectively.

\section{Immobilization of GST enzyme on MNPS}

Fig. 6a and Fig. 6b show transmission electron microscopy (TEM) images of MNPs with spherical shape and minimum aggregation, as warranted by electrostatic repulsion among negatively charged carboxylate groups on their surface. The average particle size is $7.6 \pm 1.5 \mathrm{~nm}$, according to the inset in Fig. 6a. The XRD diffractogram in Fig. $6 \mathrm{c}$ contains peaks at $2 \theta=30.7^{\circ}, 35.6^{\circ}, 43.2^{\circ}, 57.2^{\circ}$ and $62.9^{\circ}$ assigned to (220), (311), (400), (511), (440), which match in position and relative intensity the typical pattern of the cubic inverse spinel structure of magnetite [25-27]. These results are consistent with the electron diffraction pattern (ED) in Fig. 6d, and with the literature [28].

The identification of carboxyl groups on the MNPs was obtained through Fig. S2 in the Supporting Information, where the FTIR spectrum featured Fe-O stretching, symmetric and asymmetric stretching of carboxylate vibrational modes at 570, 1400 and $1600 \mathrm{~cm}^{-1}$, respectively. A band at $3300 \mathrm{~cm}^{-1}$ is due to hydroxyl groups also present on the nanoparticles surface [29-31]. With the MNPs successfully modified by carboxylate groups, as shown in the FEG-SEM image in Fig. 7a, GST could be immobilized onto the MNPs, and this is seen through the agglomerates in Fig. 7b, where the picture in the inset demonstrates that nanoparticle separation is feasible by means of magnetic interaction.

\section{Electrochemical monitoring of DO37 and GSH reaction}

In order to monitor the reaction via an electrochemical method, the magnetic particles described above were used to preconcentrate GST on the electrode surface. Fig. 8 confirms the GST immobilization on the MNPs, where a peak is observed at $0.65 \mathrm{~V}$ owing to oxidation of sulfhydryl groups [22] from GST (red line), which is not present for MNPs without GST (black line).

The reaction between DO37 and GSH eliminates the oxidation peak of sulfhydryl groups (also present in GSH), as indicated in the differential pulse voltammograms (DPV) in Fig. 9 obtained for magneto graphite-epoxy electrode modified with MNPs and GST containing $1 \mathrm{mmol} \mathrm{L}^{-1}$ GSH before (black line) and $4 \mathrm{~min}$ after addition of $0.1 \mathrm{mmol} \mathrm{L}^{-1}$ of DO37 (red line). This behavior is similar to that described by Brett et al. [22] for GSH in the presence of 1-chloro-2,4dinitrobenzene (CDNB) catalyzed by GST, which we have confirmed in subsidiary experiments with our electrode system in Fig. S3. GST 


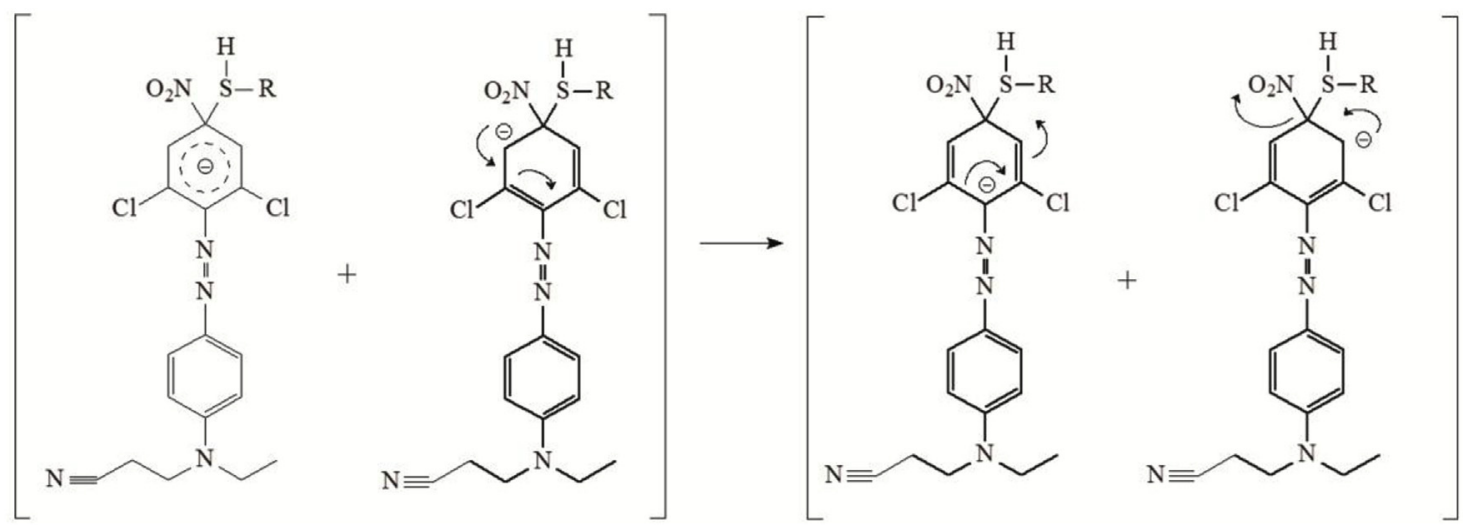

Fig. 11. Mechanism for the reaction between GSH and DO37 catalyzed by GST enzyme.

catalyzes the conjugation reaction of GSH and DO37, which probably involves the oxidizable sulfhydryl groups available only in free GSH. With the purpose of elucidating the reaction mechanism and the influence from cysteine we made this amino acid to react with DO 37, without GST. There was no reduction peak of the dye (Fig. S4), owing to a conjugation as depicted in the Supporting Information. In control subsidiary experiments we noted that: $i$ ) DO37 is not oxidized on the unmodified electrode at $0.65 \mathrm{~V}$ (Fig. S5 and S6), ii) GST accelerates reaction between DO37 and GSH (Fig. S7), iii) GSH also reacts with other azo dyes (Fig. S8), and iv) GSH better catalyzes azo dye reaction than cysteine (Fig. S9).

The oxidation peak at $0.65 \mathrm{~V}$ decreases with DO37 concentration, as expected. This is illustrated in Fig. 10, which also shows an oxidation peak at $0.91 \mathrm{~V}$ when DO37 is added, assigned to GSH-DO37 conjugation. The latter peak increases linearly with D037 concentration in the range investigated, as shown in Fig. S10. We should note that the peak at $0.9 \mathrm{~V}$ was not observed in Fig. 9 because the DO37 concentration was so high that the reaction had been completed.

The proposed mechanism for a reaction between DO37 and GSH is shown in Fig. 11. It was conceived based on experimental evidence from the literature and from the results presented in this paper. GST is known to catalyze the nucleophilic substitution reaction of the tripeptide glutathione (GSH) to compounds that have electrophilic functional groups [32], which is the DO37 in the present case.

\section{Conclusion}

The body of data presented in this paper shows unequivocally that the azo dye DO37 affects the enzyme glutathione-s-transferase (GST) and reduced glutathione (GSH). DO37 reacted with GSH and was bleached, in a reaction that was shown to be catalyzed by GST. The groups involved in the reaction could be identified with FTIR spectroscopy. For the UV-Vis and FTIR spectra, theoretical confirmation was afforded by DFT calculations. Also significant is that the reaction product was identified in electrochemical measurements, for which preconcentration of the product was achieved by immobilizing GST on magnetic nanoparticles (MNPs). The oxidation of sulfhydryl groups from GSH was the process used for monitoring the reaction induced by DO37, from which one may infer that the relatively inexpensive electrochemical methods are simple ways for monitoring reactions of proteins with toxic compounds such as dyes. The biological implications from these results are clear. If DO37 is capable of interacting strongly with both GST and GSH, it will be toxic to the liver and may trigger oncogenesis processes owing to the dye binding to the detoxification enzyme. Indeed, the binding of azo dyes to liver proteins induced hepatomas, which contain more desoxyribonucleic acid than normal tissues, and led to cirrhosis and other liver damage [33]. By determining the effects from DO37 we hope to have contributed to establish the role of GST in the metabolism of dyes and other xenobiotic compounds, whose toxicity and influence on the development and progression of cancer can now be better understood.

\section{Acknowledgements}

E.M.M. thanks FAPESP Grant 2016/00991-5. F.M.S. thanks FAPESP Grant 2012/15543-7. O.N.O. Jr. thanks FAPESP Grants (2013/142627), CNPq, CAPES, and MCTI-SisNano (Brazil).

\section{Appendix A. Supplementary data}

Supplementary data related to this article can be found at http://dx. doi.org/10.1016/j.ab.2018.05.016.

\section{Supplementary Information}

Complementary characterization of nanoparticles, theoretical UV-Vis spectra and electrochemical experiments.

\section{References}

[1] M. Solís, A. Solís, H.I. Pérez, N. Manjarrez, M. Flores, Microbial decolouration of azo dyes: a review, Process Biochem. 47 (12) (2012) 1723-1748, http://dx.doi.org/10. 1016/j.procbio.2012.08.014.

[2] P.A. Carneiro, G.A. Umbuzeiro, D.P. Oliveira, M.V.B. Zanoni, Assessment of water contamination caused by a mutagenic textile effluent/dye house effluent bearing disperse dyes, J. Hazard Mater. 174 (1-3) (2010) 694-699, http://dx.doi.org/10. 1016/j.jhazmat.2009.09.106.

[3] T. Ohe, T. Watanabe, K. Wakabayashi, Mutagens in surface waters: a review, Mutat. Res. 567 (2004) 109-149, http://dx.doi.org/10.1016/j.mrrev.2004.08.003.

[4] D. Cui, G. Li, D. Zhao, X. Gu, C. Wang, M. Zhao, Microbial community structures in mixed bacterial consortia for azo dye treatment under aerobic and anaerobic conditions, J. Hazard Mater. 221-222 (2012) 185-192, http://dx.doi.org/10.1016/j. jhazmat.2012.04.032.

[5] D.P. Oliveira, P.A. Carneiro, C.M. Rech, M.V.B. Zanoni, L.D. Claxton, G.A. Umbuzeiro, Mutagenic compounds generated from the chlorination of disperse azo-dyes and their presence in drinking water, Environ. Sci. Technol. 40 (21) (2006) 6682-6689, http://dx.doi.org/10.1021/es061020p.

[6] G.A. Umbuzeiro, D.A. Roubicek, P.S. Sanchez, M.I.Z. Sato, The Salmonella mutagenicity assay in a surface water quality monitoring program based on a 20-year survey, Mutat. Res. Genet. Toxicol. Environ. Mutagen 491 (1-2) (2001) 119-126, http://dx.doi.org/10.1016/S1383-5718(01)00139-5.

[7] D.P. Oliveira, P.A. Carneiro, M.K. Sakagami, M.V.B. Zanoni, G.A. Umbuzeiro, Chemical characterization of a dye processing plant effluent-Identification of the mutagenic components, Mutat. Res. Genet. Toxicol. Environ. Mutagen 626 (1-2) (2007) 135-142, http://dx.doi.org/10.1016/j.mrgentox.2006.09.008.

[8] T.H. Yu, A.L. Dafre, G. de Aragão Umbuzeiro, E. Franciscon, CYP-dependent induction of glutathione S-transferase in Daphnia similis exposed to a disperse azo dye, Ecotoxicology 24 (1) (2015) 232-237, http://dx.doi.org/10.1007/s10646014-1348-x.

[9] D.M. Townsend, K.D. Tew, The role of glutathione-S-transferase in anti-cancer drug resistance, Oncogene 22 (47) (2003) 7369-7375, http://dx.doi.org/10.1038/sj.onc. 1206940.

[10] W.J.P. Neish, Significance of bound dye and glutathione for aminoazo dye hepatocarcinogenesis, Chem. Biol. Interact. 3 (2) (1971) 109-116, http://dx.doi.org/10. 1016/0009-2797(71)90090-1. 
[11] W.J.P. Neish, H.M. Davies, P.M. Reeve, Carcinogenic azo dyes, dye-binding and liver glutathione, Biochem. Pharmacol. 13 (9) (1964) 1291-1303, http://dx.doi. org/10.1016/0006-2952(64)90230-8.

[12] W.J.P. Neish, E.W. Parry, F.N. Ghadially, Tumour induction in the rat by a mixture of two non-carcinogenic aminoazo dyes, Oncology 21 (3) (1967) 229-240.

[13] R. Massart, US Patent 4329241 (1982).

[14] A. Erdem, M.I. Pividori, A. Lermo, A. Bonanni, M. del Valle, S. Alegret, Genomagnetic assay based on label-free electrochemical detection using magnetocomposite electrodes, Sensor. Actuator. B Chem. 114 (2) (2006) 591-598, http:// dx.doi.org/10.1016/j.snb.2005.05.031.

[15] D.G. Pinacho, F. Sánchez-Baeza, M.-I. Pividori, M.-P. Marco, Electrochemical detection of fluoroquinolone antibiotics in milk using a magneto immunosensor, Sensors 14 (9) (2014) 15965-15980, http://dx.doi.org/10.3390/s140915965.

[16] N. Xia, Y. Xing, G. Wang, Q. Feng, Q. Chen, H. Feng, Probing of EDC/NHSSmediated covalent coupling reaction by the immobilization of electrochemically active biomolecules, Int. J. Electrochem. Sci. 8 (2013) 2459-2467.

[17] M.G.R. Pimenta-Martins, R.F. Furtado, L.G.D. Heneine, R.S. Dias, M. de Fátima Borges, C.R. Alves, Development of an amperometric immunosensor for detection of staphylococcal enterotoxin type A in cheese, J. Microbiol. Meth. 91 (1) (2012) 138-143, http://dx.doi.org/10.1016/j.mimet.2012.05.016.

[18] J.H. Keen, W.H. Habig, W.B. Jakoby, Mechanism for the several activities of the glutathione S-Transferases, J. Biol. Chem. 251 (20) (1976) 6183-6188.

[19] W.H. Habig, M.J. Pabst, W.B. Jakoby, Glutathione S-transferases. The first enzymatic step in mercapturic acid formation, J. Biol. Chem. 249 (22) (1974) 7130-7139.

[20] S. Jana, S. Mandlekar, Role of phase II drug metabolizing enzymes in cancer chemoprevention, Curr. Drug Metabol. 10 (6) (2009) 595-616, http://dx.doi.org/10. 2174/138920009789375379.

[21] T.H. Rushmore, A.-N.T. Kong, Pharmacogenomics, regulation and signaling pathways of phase I and II drug metabolizing enzymes, Curr. Drug Metabol. 3 (5) (2002) 481-490, http://dx.doi.org/10.2174/1389200023337171.

[22] T.A. Enache, A.M. Oliveira-Brett, Electrochemical evaluation of glutathione Stransferase kinetic parameters, Bioelectrochemistry 101 (2015) 46-51, http://dx doi.org/10.1016/j.bioelechem.2014.07.002.

[23] J.R. Lakowicz, Principles of Fluorescence Spectroscopy, third ed., Springer, Boston,
2006, http://dx.doi.org/10.1007/978-0-387-46312-4.

[24] X.-J. Guo, A.-J. Hao, X.-W. Han, P.-L. Kang, Y.-C. Jiang, X.-J. Zhang, The investigation of the interaction between ribavirin and bovine serum albumin by spectroscopic methods, Mol. Biol. Rep. 38 (6) (2011) 4185-4192, http://dx.doi. org/10.1007/s11033-010-0539-7.

[25] E. Solano, C. Frontera, T. Puig, X. Obradors, S. Ricart, J. Ros, Neutron and X-ray diffraction study of ferrite nanocrystals obtained by microwave-assisted growth. A structural comparison with the thermal synthetic route, J. Appl. Crystallogr. 47 (1) (2014) 414-420, http://dx.doi.org/10.1107/S1600576713032895.

[26] R. Rastogi, N. Gulati, R.K. Kotnala, U. Sharma, R. Jayasundar, V. Koul, Evaluation of folate conjugated pegylated thermosensitive magnetic nanocomposites for tumor imaging and therapy, Colloids Surfaces B Biointerfaces 82 (1) (2011) 160-167, http://dx.doi.org/10.1016/j.colsurfb.2010.08.037.

[27] M. Abu Bakar, W. Tan, N. Abu Bakar, A simple synthesis of size-reduce magnetite nano-crystals via aqueous to toluene phase-transfer method, J. Magn. Magn Mater. 314 (1) (2007) 1-6, http://dx.doi.org/10.1016/j.jmmm.2007.01.018.

[28] D. Zhang, J. Zheng, Z. Tong, Fabrication and characterisation of $\mathrm{Fe} 3 \mathrm{O} 4$ nanowires via an ethylenediamine-assisted route, J. Exp. Nanosci. 5 (2) (2010) 162-168, http://dx.doi.org/10.1080/17458080903383316.

[29] R.M. Silverstein, F.X. Webster, D.J. Kiemle, Spectrometric Identification of Organic Compounds, sixth ed., Wiley, 2004.

[30] L. Li, K.Y. Mak, C.W. Leung, K.Y. Chan, W.K. Chan, W. Zhong, P.W.T. Pong, Effect of synthesis conditions on the properties of citric-acid coated iron oxide nanoparticles, Microelectron. Eng. 110 (2013) 329-334, http://dx.doi.org/10.1016/j.mee.2013. 02.045 .

[31] E. Cheraghipour, A.M. Tamaddon, S. Javadpour, I.J. Bruce, $\{$ PEG $\}$ conjugated citrate-capped magnetite nanoparticles for biomedical applications, J. Magn. Magn Mater. 328 (2013) 91-95, http://dx.doi.org/10.1016/j.jmmm.2012.09.042.

[32] B. Ketterer, Detoxication reactions of glutathione and glutathione transferases, Xenobiotica 16 (10/11) (1986) 957-973, http://dx.doi.org/10.3109/ 00498258609038976.

[33] A.C. Griffin, W.N. Nye, L. Noda, J.M. Luck, Tissue proteins and carcicogenesis; the effect of carcinogenic azo dyes on liver proteins, J. Biol. Chem. 176 (1948) 1225-1235. 